Gulawentah: Jurnal Studi Sosial

ISSN 2528-6293 (Print); ISSN 2528-6871 (Online)

Vol. 6, No. 1, Juni 2021, Hal 42-53

Tersedia Online: http://e-journal.unipma.ac.id/index.php/gulawentah

\title{
Analisis gaya kepemimpinan spiritual dalam memimpin kemandirian unit usaha Pondok Pesantren Nurul Haramain Nadhatul Watan
}

\author{
Fajar Surya Ari Anggara*1, Lalu Fannany Farody Abar ${ }^{1}$ \\ ${ }^{1}$ Indonesia Program Studi Manajemen, Universitas Darussalam Gontor, Siman, \\ Ponorogo, Indonesia \\ Email:* fajarsurya@unida.gontor.ac.id; lalufannanyfarodyalbar@gmail.com
}

Naskah diterima: 02/05/2021; Revisi: 17/05/2021; Disetujui: 19/06/2021

\begin{abstract}
Abstrak
Tujuan penelitian ini adalah untuk menganalisis pelaksanaan kepemimpinan spritual di unit bisnis pada pesantren Nurul Haramain Nadhatul Wathan Narmada Narmada. Penelitian ini juga menganalisis strategi kepemimpinan spritual di unit bisnis pada pesantren Nurul Haramain Nadhatul Wathan Narmada. Metode pengumpulan data dalam penelitian ini menggunakan metode wawancara, observasi langsung, dan dokumentasi dari perusahaan. Direktur unit usaha Narmada Pondok Pesantren Nurul Haramain Nadhatul Wathan, Ustadz. H. Ahmad Dahlan, SH. Kemudian peneliti mewawancarai penanggung jawab Haramain Bakery, Haramain Mini Bank, unit usaha Haramain Mart, staf yang mengikuti proses kegiatan di unit-unit bisnis tersebut, dan santri. Implementasi enam indikator kepemimpinan spiritual, yaitu visi, harapan atau iman, cinta altuaristik, keterpanggilan, keanggotaan, dan kehidupan batin yang telah dilaksanakan dengan baik di unit usaha Pondok Pesantren Nurul Haramain Nadhatul Wathan Narmada. Dapat disimpulkan bahwa kepemimpinan spiritual unit usaha Pondok Pesantren Nurul Haramain Nadhatul Wathan Narmada telah dilaksanakan dengan baik. Hal ini terlihat dari enam indikator kepemimpinan spiritual yang telah dilaksanakan dengan baik di Divisi Nadhatul Wathan Pondok Pesantren Nurul Haramain yaitu visi, harapan atau keyakinan, cinta tanpa pamrih, panggilan, keanggotaan dan pelaksanaan kehidupan batin. Strategi kepemimpinan spiritual Nadhatul Wathan Narmada unit usaha Pondok Pesantren Nurul Haramain merupakan pimpinan unit usaha yang sangat memperhatikan dan meningkatkan kerohanian para anggotanya dengan memberikan motivasi dan bimbingan di lingkungan pesantren. pertemuan. Serta visi yang berdampak positif dan kuatnya harapan dan keyakinan anggota, serta rasa cinta dan kasih sayang pemimpin terhadap anggota, sebagian anggota merasa bahwa tanggung jawab ini merupakan panggilan dan keanggotaan yang baik antara pemimpin dan anggota.
\end{abstract}

Kata kunci: kepemimpinan spiritual; kemandirian; unit usaha pondok

\section{Analysis of spiritual leadership style in leading self reliance of Pondok Pesantren Nurul Haramain Nadhatul Wathan business unit}

\begin{abstract}
The purpose of this research is to analyze the implementation of spritual leadership in the business unit at the pesantren Nurul Haramain Nadhatul Wathan Narmada Narmada Narmada. This study also analyzed the strategy of spritual leadership in the business unit at nurul
\end{abstract}

DOI: $10.25273 /$ gulawentah.v6i1.9239

Some rights reserved. 
haramain nadhatul wathan narmada pesantren. The data collection method in this study uses interview methods, direct observation, and documentation from the company. Director of narmada business unit Pondok Pesantren Nurul Haramain Nadhatul Wathan, Ustadz. H. Ahmad Dahlan, SH. Then researchers interviewed the person in charge of Haramain Bakery, Haramain Mini Bank, Haramain Mart business unit, staff who follow the process of activities in these business units, and students. Implementation of six indicators of spiritual leadership, namely vision, hope or faith, altuaristic love, calling, membership, and inner life that have been implemented well in the business unit of Pondok Pesantren Nurul Haramain Nadhatul Wathan Narmada. It can be concluded that the spiritual leadership of pondok Pesantren Nurul Haramain Nadhatul Wathan Narmada business unit has been well implemented. This can be seen from the six indicators of spiritual leadership that have been implemented well in the Nadhatul Wathan Division of Pondok Pesantren Nurul Haramain namely vision, hope or belief, selfless love, vocation, membership and implementation of inner life.Nadhatul Wathan Narmada's spiritual leadership strategy of Pondok Pesantren Nurul Haramain business unit is a business unit leader who pays great attention and improves the spirituality of its members by providing motivation and guidance in the pesantren environment. meeting. As well as a vision that positively impacts and strengthens members' hopes and beliefs, as well as the leader's love and affection for members, some members feel that this responsibility is a good calling and membership between leaders and members.

Keywords: spiritual leadership; independence; business unit of pesantren

\section{Pendahuluan}

Spiritualitas berasal dari batin seseorang, menguntungkan diri sendiri dan orang lain, menciptakan keselarasan tujuan dan manusia. Gerakan Spiritual dalam suatu organisasi ini berbeda dengan hanya mematuhi aturan dan mematuhi perintah. Spiritualitas tidak terdapat dalam pikiran saja dan menciptakan makna batin dan motivasi tentang pekerjaan yang memperpanjang kedamaian batin (Mehta \& Joshi, 2000).

Efek kepemimpinan spiritual dalam membangun rasa pemimpin dan pengikut kesejahteraan spiritual ini adalah untuk menciptakan nilai di seluruh tingkat strategis, diberdayakan, dan individu untuk, pada akhirnya, menumbuhkan tingkat kesehatan manusia positif karyawan yang lebih tinggi, kesejahteraan psikologis dan spiritual, komitmen organisasi, produktivitas dan, pada akhirnya kinerja organisasi. Menurut Fry (2003) kepemimpinan spiritual merupakan pembentukan nilai, sikap, dan perilaku yang dibutuhkan untuk memotivasi diri sendiri dan orang lain secara intrinsic sehingga diharapkan mencapai rasa spiritual dalam melaksanakan tugas. Spiritual leadership comprises the values, attitudes, and behaviors required to intrinsically motivate one's self and others in order to have a sense of spiritual well-being through calling and membership (Fry, 2003).

Seseorang dengan keinginan alami untuk membantu maupun memimpin orang lain tumbuh, belajar, dan berhasil sambil menghormati dan menilai martabat individu dan kelompok. Salah satu faktor pendorong terjadinya berbagai praktik dan bisnis kepemimpinan yang tidak etis adalah karena kecenderungan masyarakat Indonesia, termasuk para pemimpin, yang lebih peduli pada nilai materialisme daripada spiritualisme (Udin, 2019).

Kerangka teori dalam penelitian ini merupakan kepemimpinan spiritual melibatkan memotivasi dan menginspirasi para pemimpin dan anggota untuk mencintai 
serta melayani orang lain berdasarkan nilai-nilai agama dalam sebuah organisasi maupun unit usaha pesantren (Andriyani, 2019; Faradisi \& Anggara, 2020; Hastuti \& Anggara, 2017; Rahmat \& Juwana, 2018). Sejauh ini, teori kepemimpinan spiritual telah diuji di berbagai organisasi, termasuk sekolah, universitas, militer, pemerintah kota, polisi, dan organisasi nirlaba (Dehaghi et al., 2012; Fry et al., 2011; Pujiastuti, 2014; Rameli et al., 2014; Samul, 2019). Penelitian penelitian tersebut menunjukkan bahwa gaya kepemimpinan spiritual berpengaruh terhadap berbagai kinerja produktivitas karyawan, kepuasan kerja karyawan, komitmen pekerja dan produktivitas unit kerja, bahkan dalam aspek pemasaran menunjukkan pertumbuhan dari segi penjualan. Budaya organisasi yang berorientasi spiritual bergantung kepada bagaimana gaya pemimpin organisasi tersebut. Hal ini menjadi menarik untuk diteliti perihal gaya kepemimpinan spiritual dalam memimpin unit usaha pondok untuk menciptakan budaya mandiri yang masih berorientasi nilai spiritual. Landasan kepemimpinan spiritual adalah mendorong nilai-nilai moral para pemimpin dan mendorong mereka untuk mengembangkan semangat tim di antara karyawan melalui harapan, saling percaya, berbagi, kerja sama, dan tujuan yang kuat, sehingga membentuk rasa memiliki organisasi di antara karyawan (Yulianti, 2018). Pesantren tradisional dipimpin para kiai yang mengajarkan buku pelajaran Islam klasik dengan metode sorogan, yaitu proses belajar mengajar di mana para kiai secara pribadi menyapa siswa (dikenal sebagai santri) atau sekelompok kecil santri di tingkat dasar (Masqon, 2011).

Permasalahan dalam kinerja pegawai unit usaha pondok pesantren menunjukkan perlunya analisis manajemen dan kepemimpinan bagaimana peran pemimpin dalam mengarahkan sumber daya manusia. Bagaimana langkah pimpinan menyelesaikan berbagai masalah yang dialami oleh unit usaha pondok pesantren diperlukan pendekatan berbasis spiritual. Kepemimpinan spiritual bagaimana gaya kepemimpinan yang mengutamakan moralitas, kepekaan (sensitivity), keseimbangan psikologis, kekayaan spiritual, dan moralitas ketika berinteraksi antar pemimpin maupun anggota dalam organisasi yang dipimpin. Pentingnya menganalisis kepemimpininan spiritual di Unit Usaha Pondok Pesantren agar dapat diperoleh bagaimana pendekatan kepemimpinan yang dapat mempengaruhi segenap anggota yang dipimpin untuk melakukan yang terbaik dalammencapai kesempurnaan batin sesuai dengan nilai-nilai kehidupan yang diyakini. Peran spiritual leadership inilah yang menjadi penting dibutuhkan oleh seorang pemimpin dalam mengatasi hal-hal yang semacam itu. Unit usaha untuk meningkatkan keuntungan bagi pesantren, juga menjadi tempat bagi santri untuk belajar kewirausahaan dan kepemimpinan. Dari uraian tersebut, peneliti ingin mendapatkan gambaran yang lebih mendalam dan membahasnya secara lebih rinci bagaimana gaya kepemimpinan spiritual dalam memimpin kemandirian Unit Usaha Pondok Pesantren Nurul Haramain Nadhatul Wathan.

\section{Metode Penelitian}

Jenis penelitian yang digunakan dalam penelitian ini menggunakan jenis penelitian kualitatif. Di mana dalam jenis penelitian kualitatif ini dilakukan ketika kondisi terjadi atau alami. Objek penelitian ini adalah unit usaha milik Pondok Pesantren Nurul Haramain Nadhatul Wathan yang berlokasi di Kecamatan Narmada, Lombok Barat. Unit usaha Pesantren Nurul Haramain memiliki tiga item unit bisnis yang berbeda, yaitu Haramain Mart, Haramain Mini Bank, dan Haramain Bakery. Penelitian ini bertujuan untuk menganalisa pelaksanaan kepemimpinan spritual di unit usaha pada pesantren Nurul Haramain Nadhatul Wathan Narmada Narmada. Penelitian 
ini juga menganalisa strategi kepemimpinan spritual di unit bisnis di pondok pesantren Nurul Haramain Nadhatul Wathan Narmada Narmada dalam kurun waktu bulan November 2020 sampai Maret 2021.

Sebagai sampel atau informan dalam penelitian ini mencakup Direktur unit usaha Narmada Pondok Pesantren Nurul Haramain Nadhatul Wathan, Ustadz. H. Ahmad Dahlan, SH. Kemudian peneliti mewawancarai penanggung jawab Haramain Bakery, Haramain Mini Bank, unit usaha Haramain Mart, staf yang mengikuti proses kegiatan di unit-unit bisnis tersebut, dan santri yang terlibat di unit usaha pada pesantren Nurul Haramain Nadhatul Wathan Narmada Narmada. Penelitian ini juga menganalisa strategi kepemimpinan spritual di unit bisnis di pondok pesantren Nurul Haramain Nadhatul Wathan Narmada Narmada. Unit bisnis dikelola oleh santri baik anak laki-laki maupun perempuan. Pengelola masing-masing unit usaha yang dipegang oleh ulama dan ulama. Unit usaha pesantren Nurul Haramain Nadhatul Wathan dikepala oleh AlUstadz Ahmad Dahlan yang merupakan guru senior di pondok tersebut. Sedangkan prosedur wawancara secara semi terstruktur dan mendalam dalam penelitian ini memiliki tujuh tahapan yaitu, menentukan objek atau kepada siapa wawancara akan dilakukan, menyiapkan pokok permasalahan yang akan dibahas, memulai dan atau membuka alur wawancara, menginformasikan ringkasan hasil wawancara, menulis wawancara ke dalam catatan, dan mengidentifikasi tindak lanjut wawancara yang telah diperoleh.

Setelah mendapatkan data yang diperoleh melalui observasi, wawancara dan dokumentasi, langkah selanjutnya adalah melakukan analisis data. Dalam penelitian ini untuk menganalisis data melalui beberapa tahapan, tahap pertama analisis data dilakukan sebelum memasuki lapangan, kemudian tahap kedua saat di lapangan dan bertemu dengan objek atau responden, dan terakhir setelah menyelesaikan lapangan. Analisis selama di lapangan menggunakan model Miles dan Huberman dimana pada saat wawancara peneliti telah melakukan analisis terhadap jawaban yang diwawancarai. Dan menurut Miles dan Huberman kegiatan dalam kegiatan analisis data adalah reduksi data, penyajian data, penarikan kesimpulan atau verifikasi.

Teknik pemeriksaan keabsahan data yang digunakan dalam penelitian ini adalah teknik Triangulasi. Teknik triangulasi adalah teknik pemeriksaan keabsahan data yang memanfaatkan sesuatu selain data. Dalam penelitian ini peneliti menggunakan teknik pengecekan keabsahan data triangulasi sumber dan triangulasi metode. Dengan teknik triangulasi sumber, peneliti membandingkan hasil wawancara yang diperoleh dari masing-masing sumber atau informan penelitian sebagai pembanding untuk mengecek kebenaran informasi yang diperoleh. Selain itu peneliti juga mengecek derajat kepercayaan melalui teknik triangulasi dengan metode yaitu dengan cara mengecek hasil penelitian dengan teknik pengumpulan data yang berbeda yaitu wawancara, observasi, dan dokumentasi hasil penelitian unit bisnis di pondok pesantren Nurul Haramain.

\section{Hasil dan Pembahasan \\ Hasil Penelitian}

Unit bisnis Pondok Pesantren Nurul Haramain Nadhatul Wathan Narmada merupakan organisasi untung milik Pondok Pesantren Nurul Haramain Nadhatul Wathan Narmada Lombok Barat. Dimana Pondok Pesantren Nurul Haramain Nadhatul 
Wathan Narmada merupakan organisasi nirlaba yang bergerak di bidang pendidikan. Pondok Pesantren Nurul Haramain Nadhatul Wathan Narmada didirikan oleh Kiyai Haji Tuan Guru (TGKH) Djuaini Mukhtar pada tahun 1991 di Desa Lembuak, Kecamatan Narmada, Kabupaten Lombok Barat.

Untuk mendukung proses kegiatan pesantren, dibuat unit usaha sebagai media untuk menunjang kebutuhan pesantren dan kebutuhan siswa dan siswi perempuan di mana pondok pesantren Nurul Haramain Nadhatul Wathan Narmada memiliki 2.357 siswa yang berada di empat kampus. Ini adalah kompleks kampus untuk mahasiswa anak laki-laki, kompleks kampus untuk mahasiswa perempuan, kompleks kampus kedua untuk mahasiswa perempuan, dan Madani Super Camp Place untuk menjalankan program karantina untuk menghafal Al-Qur'an dan mengkarantina program kursus bahasa Inggris. Unit usaha ini juga menjadi media bagi mahasiswa yang belajar kewirausahaan sekaligus sumber pendanaan kedua setelah adanya kontribusi dari wali murid untuk mendukung kemandirian pondok pesantren.

Terdapat tiga unit usaha pondok pesantren yang menjadi objek dalam penelitian ini. Haramain Mart adalah unit bisnis yang bergerak di sektor ritel, di mana unit usaha ini menjual semua kebutuhan mahasiswa dan masyarakat. Haramain Mart adalah unit bisnis paling tua karena telah berjalan 10 tahun. Namun karena meningkatnya permintaan pasar dari mahasiswa dan masyarakat serta untuk kemajuan Pondok Pesantren Nurul Haramain Nadhatul Wathan Narmada sendiri. Pada 28 November 2018, Haramain Mart membuka ritel baru di luar pondok. Haramain Mini Bank adalah unit usaha yang bergerak di bidang tabungan dan jasa pinjaman. Haramain Mini Bank didirikan pada tahun 2015 dan berpusat di Pondok Pesantren Nurul Haramain Nadhatul Wathan Komdis Narmada untuk kampus pelajar laki-laki. Tujuan Dari Haramain Mini Bank adalah untuk menciptakan kelompok usaha kreatif dan menghubungkan kegiatan usaha dengan wisata halal dan syariah atau sistem keuangan syariah. Mitra Haramain Mini Bank adalah perbankan syariah, guru dan siswa, serta institusi pendidikan lainnya di sekitar wilayah distrik Narmada. Produk Bank Mini Haramain adalah Modal Usaha, Tabungan Haji, Tabungan Qurban, Tabungan Perkawinan, dan Kredit Sepeda Motor, dan lain-lain. Haramain Bakery merupakan unit usaha yang diinisiasi oleh meningkatnya tuntutan Pondok Pesantren Nurul Haramain Nadhatul Wathan Narmada khususnya untuk konsumsi dan kebutuhan masyarakat Narmada pada umumnya karena pusat roti dan kue berada di wilayah kota Mataram. Oleh karena itu, pada awal tahun 2019, Haramain Bakery resmi berdiri, di mana tempat tersebut berada selain Haramain Mart di jalan raya Narmada-Sesaot. Pada awal berdirinya Toko Roti Haramain hanya memiliki lima varian produk roti dan kue dan hanya didistribusikan di kampus kompleks untuk anak laki-laki dan perempuan Pondok Pesantren Nurul Haramain Nadhatul Wathan Narmada. Tetapi sekarang Haramain Bakery memiliki tiga puluh dua produk roti dan kue Farian tersedia dalam output dan didistribusikan juga ke kantin di lembaga pendidikan di sekitar daerah wilayah Narmada. 


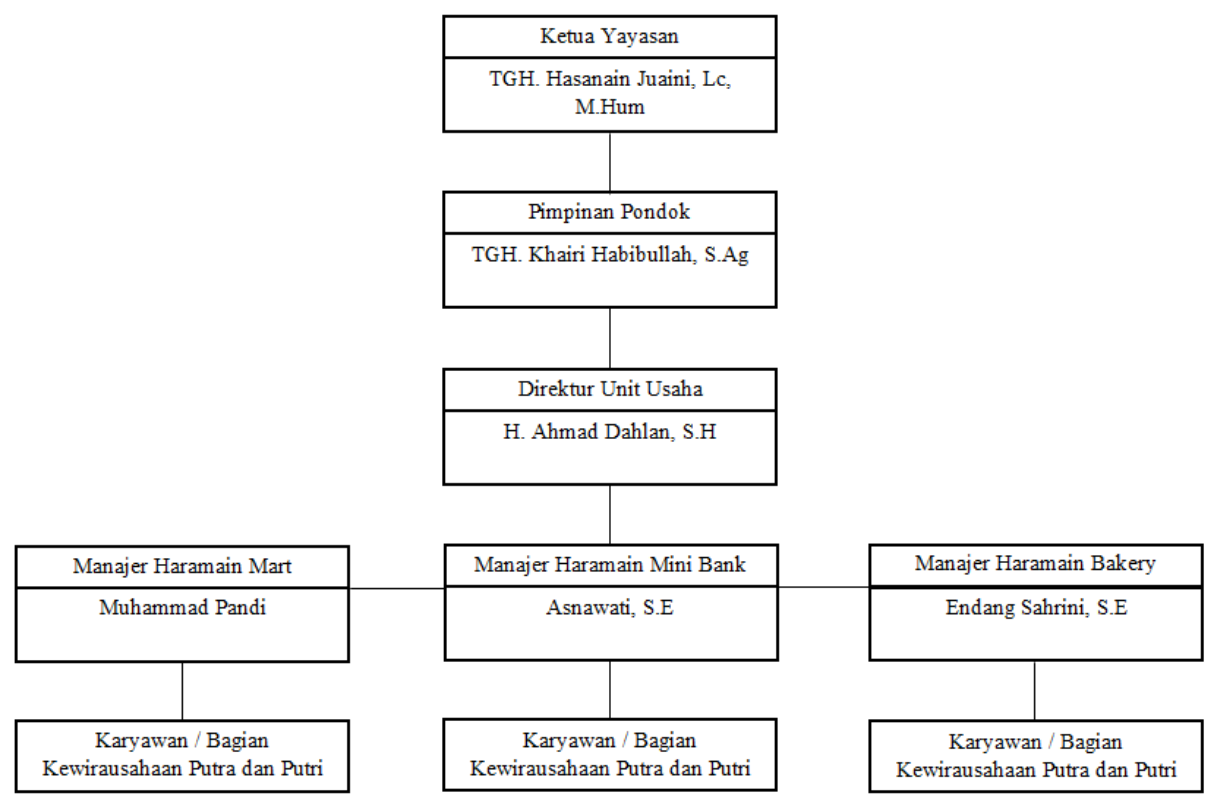

Sumber: dokumentasi penelitian (2021)

\section{Gambar 1. Bagan Stuktur Organisasi Unit Usaha Pondok Pesantren Nurul Haramain Nadhatul Wathan Narmada}

\section{Visi}

Unit usaha Pondok Pesantren Nurul Haramain Nadhatul Wathan (Narmada) memiliki visi yang sama dengan visi Pesantren Nurul Haramain Nadhatul Wathan Narmada yang baik, benar, bermanfaat, dan sejahtera. Seperti yang dikatakan oleh Ustadz Ahmad Dahlan selaku direktur bisnis saat diwawancarai yang mengatakan "Ya, karena berawal dari visi pondok, visi pondok itu baik, benar, bermanfaat, dan sejahtera". Pondok ini memiliki visi sebagai lembaga pendidikan pencetak kader-kader pemimpin umat, menjadi tempat ibadah talab al-'ilmi, dan menjadi sumber pengetahuan Islam, bahasa al-Qur'an, dan ilmu pengetahuan umum, dengan tetap berjiwa pesantren. Hasil wawancara dan observasi menunjukkan nilai-nilai spiritual dalam kepemimpinan dapat memotivasi dan memotivasi karyawan untuk membentuk visi dan budaya organisasi, serta menciptakan komitmen karyawan terhadap organisasi yang pada akhirnya berdampak pada peningkatan kepuasan kerja dan kinerja karyawan unit usaha Pondok Pesantren Nurul Haramain Nadhatul Wathan.

\section{Iman}

Dalam penelitian ini, peneliti meneliti empat unsur indikator harapan atau iman dalam penerapan kepemimpinan spiritual di unit usaha pada Pondok Pesantren Nurul Haramain Nadhatul Wathan Narmada. Elemen pertama adalah apakah kepemimpinan dari pemimpin sampai anggota memiliki harapan dan keyakinan dalam organisasi dan bersedia melakukan apa pun untuk tujuan organisasi. Hasil observasi dan wawancara menunjukkan bahwa kepemimpinan spiritual pada unit usaha pada Pondok Pesantren Nurul Haramain Nadhatul Wathan Narmada dapat meningkatkan dan menginspirasi iman serta hati nurani pengikut melalui pengorbanan sebagai perbuatan baik yang terus dilakukan. 


\section{Cinta alturistik}

Hasil wawancara dan observasi menunjukkan kepemimpinan spiritual unit usaha pondok pesantren nurul haramain dapat membangun budaya sosial/organisasi berdasarkan cinta tanpa pamrih Dalam budaya ini, pemimpin dan pengikut benar-benar peduli, peduli dan menghormati satu sama lain, sehingga menciptakan rasa keanggotaan dan perasaan dipahami dan dihargai. Aspek cinta altuaristik kepemimpinan spiritual yang diterapkan sebagai indikator kepemimpinan spiritual di unit usaha pada Pondok Pesantren Nurul Haramain Nadhatul Wathan Narmada. Tanpa adanya nilai cinta alturistik, banyak karyawan yang hanya bekerja untuk memenuhi kebutuhan sekuler atau ekonomi, alih-alih mencintai pekerjaan dan menikmati hidup.

\section{Perasaan}

Hasil observasi dan wawancara menunjukkan bahwa tugas dan pekerjaan yang dilaksanakan oleh segenap pemimpin dan anggota unit usaha pada Pondok Pesantren Nurul Haramain Nadhatul Wathan Narmada ini memiliki arti dan makna tersendiri, kemudian pemimpin dan anggota dalam organisasi ini melaksanakan tugas mereka dan bekerja dengan rasa panggilan, dan akhirnya apakah pekerjaan dan tugas membuat kehidupan orang yang diwawancarai berbeda dari yang lain. Anggota organisasi percaya bahwa pekerjaan yang mereka lakukan penting, bermakna dan bermakna bagi mereka, serta dapat mengubah kehidupan komunitas lain. Hasil penelitian ini meliputi pelaksanaan aspek perasaan dalam kepemimpinan spiritual di unit usaha pada Pondok Pesantren Nurul Haramain Nadhatul Wathan Narmada. Dalam penelitian tentang pelaksanaan kepemimpinan spiritual di organisasi berbasis spiritual, dimana unit usaha Pondok Pesantren Nurul Haramain Nadhatul Wathan Narmada adalah organisasi berbasis spiritual.

\section{Keanggotaan}

Hasil wawancara dan observasi menunjukkan bahwa pemimpin dalam di unit usaha pada Pondok Pesantren Nurul Haramain Nadhatul Wathan Narmad memahami kekhawatiran anggota. Pemimpin dalam organisasi ini menghargai pekerjaan dan anggota mereka, Pemimpin dalam organisasi ini menghargai pekerjaan dan anggota mereka, akhirnya apakah para pemimpin dalam organisasi ini menghormati anggota mereka. Islam menempatkan aktivitas perdagangan dalam posisi yang sangat strategis di tengah kegiatan manusia mencari rezeki dan mata pencaharian.

\section{Kehidupan batin}

Dari hasil wawancara bersama informan menunjukkan bahwa segenap anggota telah memiliki pemenuhan kehidupan batin dalam kepeimpinan spiritual, pemimpin dan anggota organisasi ini peduli dengan spiritualitas anggota mereka, pemimpin dalam organisasi ini sangat memperhatikan spiritualitas anggota mereka, dan spiritualitas sangat berpengaruh dalam menentukan atau membuat keputusan pemimpin terhadap anggota dan organisasinya. Dengan demikian, dari wawancara di atas, pelaksanaan kehidupan batin sebagai indikator kepemimpinan spiritual di Unit Usaha pada Pondok Pesantren Nurul Haramain Nadhatul Wathan Narmada telah dilaksanakan dengan baik.

Dari hasil wawancara di atas melalui wawancara enam aspek kepemimpinan spiritual. Ditemukan bahwa strategi implementasi kepemimpinan spiritual di unit usaha pada Pondok Pesantren Nurul Haramain Nadhatul Wathan Narmada adalah 
memperhatikan dan meningkatkan spiritualitas anggotanya yang kemudian mempengaruhi kepemimpinan dan daripada spiritualitas ini mempengaruhi pemimpin dan anggotanya. Kemudian visi organisasi yang berdampak positif serta kuatnya harapan dan iman para anggota serta kecintaan dan kasih sayang para pemimpin terhadap anggotanya sehingga beberapa anggota merasa tugas ini merupakan pemanggilan dan keanggotaan yang baik antara pemimpin dan anggotanya. Sehingga penerapan kepemimpinan spiritual di unit Pesantren Nurul Haramain Nadhatul Wathan Narmada telah diterapkan dengan baik sesuai dengan teori yang dikemukakan louis Fry melalui enam aspek tersebut.

\section{Pembahasan}

Peneliti membagi menjadi topik utama keenam, yaitu: Visi, Harapan atau Iman, Cinta Altuistrik, Panggilan, Keanggotaan, Kehidupan Batin. Pemimpin spiritual memiliki visi yang besar dan tidak melupakan situasi organisasi saat ini serta dapat mengarahkan dan membimbing anggotanya untuk mewujudkan visinya bersama (Mukaromah, 2018). Kepemimpinan spiritual memiliki aspek harapan / iman dalam misi organisasi membuat pengikut menantikan masa depan dan bahan bakar bekerja melalui motivasi intrinsik (Fry et al., 2007). Kemepimpinan spiritual dapat membangun budaya sosial/organisasi berdasarkan nilai-nilai cinta altruistik dimana pemimpin dan pengikut memiliki rasa keanggotaan, merasa dipahami dan dihargai, dan memiliki kepedulian, perhatian, dan penghargaan yang tulus baik untuk diri sendiri maupun orang lain (Fry \& Cohen, 2009). Kepemimpinan spiritualitas di tempat kerja, yang terdiri dari keterpanggilan dan keinginan mengarahkan anggotanya dari segi pendekatan hubungan social (Nguyen et al., 2018). Aspek keanggotaan merupakan kebutuhan dasar manusia, yaitu keinginan untuk dipahami dan keinginan untuk dihargai. Perasaan ingin dipahami dan dihargai merupakan isu penting dalam hubungan timbal balik dan interaksi sosial (Ilham, 2012). Ketetapan batin dalam kepemimpinan spiritual untuk menumbuhkan kualitas internal yang sangat baik dalam kepemimpinan, sehingga komunitas organisasi akan mendapat perhatian dan istiqomah penuh dalam menjalankan tugasnya masingmasing (Andriyani, 2019). Pelaksanaan kepemimpinan spiritual di Pondok Pesantren Nurul Haramain Nadhatul Wathan Narmada dilaksanakan dalam beberapa dimensi kepemimpinan spiritual. Ini dapat dijelaskan sebagai berikut:

\section{Visi}

Visi adalah hal yang sangat mendesak dalam organisasi apa pun, baik itu organisasi laba atau nirlaba. Karena visi akan menentukan arah dan tujuan suatu organisasi (Alimudin et al., 2017). Menurut Fry (2003) menjelaskan bahwa visi dalam sebuah organisasi juga berfungsi sebagai petunjuk besar untuk pengembangan, yaitu menjelaskan arah pengembangan secara umum, menentukan bagaimana arah keputusan terperinci, dan secara efisien mengoordinasikan tindakan banyak orang yang berbeda.

\section{Iman}

Harapan atau Iman adalah indikator kedua dalam penerapan kepemimpinan spiritual. Harapan atau Iman dalam konteks kepemimpinan spiritual adalah kepastian hal-hal yang diharapkan atau keyakinan bahwa visi, tujuan, dan misi organisasi akan terpenuhi. Anggota tim dalam Unit Usaha Pondok Pesantren Nurul Haramain ditantang untuk bertahan dan melakukan apa yang diperlukan untuk memenuhi tujuan yang alan 
datang melalui harapan maupun iman dalam visi organisasi, pemimpin mereka, dan diri mereka sendiri (Scott \& Tweed, 2016).

\section{Cinta alturistik}

Cinta alturistik dalam pelaksanaan kepemimpinan spiritual, definisi cinta altuaristik adalah bahwa rasa keutuhan, keharmonisan, dan kesejahteraan dihasilkan melalui perawatan, perhatian, dan rasa hormat terhadap diri sendiri dan orang lain. Di sinilah dibutuhkan orientasi kepemimpinan baru dalam organisasi, yaitu kepemimpinan spiritual (Puspitasari, 2019).

\section{Perasaan}

Calling atau perasaan yang memiliki makna adalah salah satu indikator kepemimpinan spiritual. Keterpanggilan dalam kepemimpinan spiritual adalah perasaan bahwa kehidupan seseorang memiliki makna dan membuat perbedaan. Panggilan karyawan untuk membangkitkan keyakinan orang dan manfaat apa yang dibawanya bagi organisasi (Violita, 2018).

\section{Keanggotaan}

Keanggotaan dalam kepemimpinan spiritual adalah perasaan bahwa seseorang di setiap anggota organisasi ingin dipahami dan dihargai. Dalam arti setiap anggota ingin terlibat atau terlibat dalam kegiatan organisasi sehingga anggota merasa dipahami dan dihargai oleh para pemimpin dan organisasi. Etika bisnis yang juga diterapkan oada BMT menekankan prinsip-prinsip yang mencerminkan tata kelola berbasis nilai seperti keamanan (security) tanggung jawab kepada seluruh anggota selain hanya prinsip keadilan, kejujuran dan kebersamaan dalam keanggotaan (Hastuti \& Anggara, 2017).

\section{Kehidupan batin}

Kehidupan batin adalah elemen penting dalam kepemimpinan spiritual karena melibatkan spiritualitas dan spiritualitas seseorang. Dalam kepemimpinan spiritual, kehidupan batin adalah sejauh mana seseorang atau anggota dalam suatu organisasi memiliki kecenderungan spiritual, di mana kecenderungan spiritual sangat mempengaruhi individu (Fry et al., 2011).

Strategi Kepemimpinan Spiritual Unit Usaha Pondok Pesantren Nurul Haramain Nadhatul Wathan Narmada merupakan pendekatan kepimpinanan yang benar-benar peduli dan membangkitkan semangat anggotanya dengan memberikan motivasi dan bimbingan saat berkumpul. Serta visi yang berdampak positif dan kuatnya harapan dan keyakinan para anggota, serta cinta dan kasih sayang pemimpin kepada anggota, beberapa anggota merasa bahwa tanggung jawab semacam ini merupakan panggilan dan keanggotaan yang baik antara anggota. pemimpin dan anggota. Strategi kepemimpinan spiritual Unit Usaha Pondok Pesantren Nurul Haramain Nadhatul Wathan Narmada mencakup aspek visi, harapan atau iman, cinta altuaristik, pemanggilan, keanggotaan, dan kehidupan batin sebagaimana aspek yang diteliti pada penelitian sebelumnya (Fry et al., 2007; Nguyen et al., 2018; Niati et al., 2020; Pujiastuti, 2014). Hal ini jelas bahwa kepemimpinan spiritual unit usaha pondok pesantren Nurul Haramain Nadhatul Wathan Narmada mencerminkan implementasi strategi kepemimpinan spiritual yang mencakup pendekatan teologis dan praktik nilai kepemimpinan berbasis agama dan moral (Basit, 2013; Fry, 2003; Fry et al., 2011; McGhee \& Grant, 2009). 


\section{Simpulan}

Kepemimpinan spiritual di Unit Bisnis di Pondok Pesantren Nurul Haramain Nadhatul Wathan Narmada telah dilaksanakan dengan baik. Hal ini terlihat dengan dilaksanakannya enam indikator kepemimpinan spiritual, yaitu visi, harapan atau iman, cinta altuaristik, pemanggilan, keanggotaan, dan kehidupan batin yang telah dilaksanakan dengan baik di unit usaha Pondok Pesantren Nurul Haramain Nadhatul Wathan Narmada. Hasil analisis menunjukkan bahwa strategi kepemimpinan spiritual di Unit Usaha Pesantren Nurul Haramain Nadhatul Wathan Narmada adalah direktur unit usaha sangat peduli dan meningkatkan spiritualitas anggotanya dengan memberikan motivasi dan arahan pada acara silaturahmi tersebut. Serta visi membuat dampak positif dan harapan serta iman yang kuat dari para anggota serta cinta dan kasih sayang para pemimpin terhadap anggota mereka sehingga beberapa anggota merasa tugas ini adalah panggilan dan keanggotaan yang baik antara pemimpin dan anggotanya. Penelitian berikutnya dapat dilakukan analisis pendalaman karakter kepemimpinan spiritual bagaimana cara para pemimpin dalam organisasi ini membangkitkan spiritualitas anggotanya untuk menjadi kader pemimpin seperti dengan lebih terpogram dalam memberikan cerita dan mengundang anggota untuk mengobrol selama pertemuan setiap pekan melalui pendekatan kualitatif dan kuantitatif Pentingnya kepemimpinan spiritual muncul dalam sosok kader pimpinan yang mampu memberikan motivasi kepada setiap pertemuan adalah cara para pemimpin dalam organisasi ini membangkitkan spiritualitas anggotanya.

\section{Daftar Pustaka}

Alimudin, A., Septian, D., Sasono, A. D., \& Wulandari, A. (2017). Effect of Spiritual Leadership to Organizational Culture and Employee's Loyalty. Jurnal Terapan $\begin{array}{llll}\text { Manajemen Dan } & \text { Bisnis, }\end{array}$ https://doi.org/https://doi.org/DOI:10.26737/jtmb.v3i2.210

Andriyani, I. N. (2019). Spiritual Leadership. Jurnal Komunikasi Dan Pendidikan Islam, 7(2), 22-26. https://doi.org/https://doi.org/10.35345/johmal.529712

Basit, A. (2013). Habitual Action Dalam Kepemimpinan Spiritual. KOMUNIKA: Jurnal $\begin{array}{lll}\text { Dakwah Komunikasi, } & \text { K(1). }\end{array}$ https://doi.org/https://doi.org/10.24090/komunika.v7i1.371

Dehaghi, M. R., Goodarzi, M., \& Arazi, Z. K. (2012). The effect of spiritual values on employees' organizational commitment and its models. Procedia-Social and Behavioral Sciences, $\quad 62, \quad 159-166$. https://doi.org/https://doi.org/10.1016/j.sbspro.2012.09.025

Faradisi, R. J., \& Anggara, F. S. A. (2020). Analysis of Islamic business ethics and its impact during the Covid19 pandemic. Al Tijarah, 6(3), 115-120. https://doi.org/http://dx.doi.org/10.21111/tijarah.v6i3.5660

Fry, L. W. (2003). Toward a theory of spiritual leadership. The leadership quarterly, 14(6), 693-727. https://doi.org/https://doi.org/10.1016/j.leaqua.2003.09.001 
Fry, L. W., \& Cohen, M. P. (2009). Spiritual leadership as a paradigm for organizational transformation and recovery from extended work hours cultures. Journal of business ethics, 84(2), 265-278. https://doi.org/https://doi.org/10.1007/s10551-008-9695-2

Fry, L. W., Hannah, S. T., Noel, M., \& Walumbwa, F. O. (2011). Impact of spiritual leadership on unit performance. The leadership quarterly, 22(2). https://doi.org/https://doi.org/10.1016/j.leaqua.2011.02.002

Fry, L. W., Nisiewicz, M., Vitucci, S., \& Cedillo, M. (2007). Transforming city government through spiritual leadership: Measurement and establishing a baseline. National Meeting of the Academy of Management, Philadelphia, Pennsylvania,

Hastuti, E. W., \& Anggara, F. S. A. (2017). Implementation of Islamic Business Ethics Values based on IFSB 09: BMT La Tansa Ponorogo Experience. Al Tijarah, 3(2), 119-134. https://doi.org/https://doi.org/10.21111/tijarah.v3i2.1935

Ilham, R. (2012). Pengaruh Spiritual Leadership Terhadap Organizational Commitment Melalui Calling Dan Membership Pada PT. Asuransi Takaful Keluarga. Jurnal Manajemen Teori dan Terapan| Journal of Theory and Applied Management, 5(1). https://doi.org/https://doi.org/10.20473/jmtt.v5i1.2447

Masqon, D. (2011). Dynamic of Pondok Pesantren as Indegenous Islamic Education Centre In Indonesia. Tsaqafah, 7(1), 155-168. https://doi.org/http://dx.doi.org/10.21111/tsaqafah.v7i1.114

McGhee, P., \& Grant, P. (2009). Virtue: The missing piece in spiritual leadership. http://hdl.handle.net/10292/2036

Mehta, Y., \& Joshi, S. (2000). Impact of workplace spirituality on organization culture through improved employee productivity. Communication Studies, 51(3). https://www.nepjol.info/index.php/JTHE/article/view/20011/16427\#: :text=The $\% 20$ study $\% 20$ concluded $\% 20$ that $\% 20$ there,the $\% 20$ employee $\% 20$ productive $\% 20$ and $\% 20$ satisfied.

Mukaromah, S. M. (2018). Kepemimpinan Spiritual (Spiritual Leadership) Guru Sekolah Dasar Dalam Pembentukan Karakter Peserta Didik. Elementary: Jurnal Ilmiah Pendidikan Dasar, 63-74. https://doi.org/https://doi.org/10.32332/elementary.v4i1.1029

Nguyen, P. V., Tran, K. T., Dao, K. H., \& Dinh, H. P. (2018). The role of leader's spiritual leadership on organisation outcomes. Asian Academy of Management Journal, 23(2). https://doi.org/https://doi.org/10.21315/aamj2018.23.2.3

Niati, N., Tanjung, H., \& Yasid, M. (2020). Prophet Muhammad (PBUH) Business Management In Organizational Development (Case Study Of Wikrama-Bogor Vocational School). Jurnal Manajemen (Edisi Elektronik), 11(1), 01-17. https://doi.org/http://dx.doi.org/10.32832/jm-uika.v11i1.2692 
Pujiastuti, R. (2014). Karakteristik Spiritual Leadership Perangkat Desa Di Kabupaten Banyumas (Berdasar Teori Spiritual Leadership Fry).

Puspitasari, S. (2019). Pengaruh kepemimpinan spiritual terhadap kepuasan kerja karyawan melalui motivasi intrinsik dan komitmen organisasi (studi kasus Rumah Sakit Islam Sultan Agung, Semarang). Jurnal Ekonomi dan Bisnis, 20(1), 73-84. https://doi.org/http://dx.doi.org/10.30659/ekobis.20.1.73-84

Rahmat, I., \& Juwana, L. (2018). Working Islamic Management: Sebuah Best Practice Internalisasi Islam Dalam Organisasi Bisnis Kuliner. JEBI (Jurnal Ekonomi dan Bisnis Islam), 3(1), 103-120.

Rameli, M. F. P., Aziz, M. R. A., Wahab, K. A., \& Amin, S. M. (2014). The Characteristics of Muslimpreneurs from the view of Muslim Scholars and Academician. International Journal of Teaching and Education, 2(2), 47-59. https://www.semanticscholar.org/paper/The-Characteristics-of-MuslimpreneursFrom-The-View-RameliAziz/58a34315845d27668bb452816b34be57a9aa952c?p2df

Samul, J. (2019). Spiritual leadership: Meaning in the sustainable workplace. Sustainability, 12(1), 1-1. https://doi.org/https://doi.org/10.3390/su12010267

Scott, P., \& Tweed, S. (2016). Implications of spiritual leadership on organizations. Journal of Education \& Social Policy, 3(6), 66-70.

Udin, U. (2019). Spiritual Leadership And Employee Performance: An Empirical Investigation. International Journal of Business Management and Economic Review, 10(4), 54-61.

Violita, D. (2018). Pengaruh gaya kepemimpinan spiritual dan budaya organisasi terhadap kinerja karyawan pada hotel 88 embong malang di Surabaya UIN Sunan Ampel Surabaya.

Yulianti, E. R. (2018). Upaya Kepemimpinan Spiritual Dalam Mengembangkan Budaya Mutu Di Sma Plus Muthahhari Bandung. Schemata: Jurnal Pasca Sarjana IAIN Mataram, $7(2)$, 128-151. https://doi.org/https://doi.org/10.20414/schemata.v7i2.515 